\title{
RELATIONSHIPS AMONG WALKING SPEED, SELECTED CLINICAL SYMPTOMS, AND EXERCISE SELF-EFFICACY IN INDIVIDUALS WITH KNEE OSTEOARTHRITIS
}

original paper

(1) University School of Physical Education in Wroclaw

DOI: https://doi.org/10.5114/hm.2019.81023

\section{OMOYEMI O. OGWUMIKE ${ }^{1,2}$, SUMAYYAH BAMIDELE MUSA ${ }^{1}$}

${ }^{1}$ Department of Physiotherapy, College of Medicine, University of Ibadan, Ibadan, Nigeria

${ }^{2}$ Department of Physiotherapy, University College Hospital, Ibadan, Nigeria

\section{ABSTRACT}

Purpose. Osteoarthritis $(\mathrm{OA})$ is characterised by a combination of joint symptoms and signs stemming from defects in the articular cartilage and adjacent tissues, such as bone, synovial joint capsule, muscles, and ligaments. Knee OA is among the most common causes of pain and disability in middle-aged and older people. This study investigated the relationships among selected clinical symptoms (pain, stiffness, physical function), walking speed, and exercise self-efficacy in individuals with knee OA in Ibadan, Nigeria.

Methods. The study involved 100 individuals diagnosed with knee OA. Exercise self-efficacy was assessed with the exercise self-efficacy scale. Pain, stiffness, and physical function were evaluated with the Western Ontario and McMaster (WOMAC) Osteoarthritis Index questionnaire. Walking speed was determined during the 20-meter walk test. Data were analysed with descriptive statistics and Pearson's correlation test, with significance level set at 0.05.

Results. Significant correlations were observed between pain intensity and walking speed $(\rho=-0.38)$, stiffness and walking speed $(\rho=-0.19)$, physical function and walking speed $(\rho=-0.40)$, pain intensity and exercise self-efficacy $(\rho=-0.43)$, stiffness and exercise self-efficacy $(\rho=-0.46)$, physical function and exercise self-efficacy $(\rho=-0.41)$. More than $50 \%$ of the participants with knee OA had low exercise self-efficacy and moderate walking speed. Individuals with higher levels of pain, stiffness, and functional limitations showed lower levels of exercise self-efficacy and lower walking speed.

Conclusions. Individuals with knee OA presented low exercise self-efficacy, low walking speed, and reduced physical function, probably because of the debilitating effects of the condition.

Key words: osteoarthritis, joint symptoms, physical function, exercise self-efficacy

\section{Introduction}

Osteoarthritis (OA) is a heterogeneous group of conditions characterised by a combination of joint symptoms and signs stemming from defects in the articular cartilage and changes in the adjacent tissues, such as bone, synovial joint capsule, muscles, and ligaments [1]. It is a common degenerative joint disorder, and its morbidity increases with ageing in both genders, especially if it affects the knee joint [2]. OA occurs all over the world, but the pattern and prevalence of the disease varies amongst nations [3]. In Nigeria, knee OA is most prevalent, followed closely by hip OA [3]. A point prevalence of symptomatic knee OA of $19.6 \%$ was reported in South West Nigeria [4].
OA can affect the main surfaces of the knee joint and the cartilage under the patella. This is probably due to the loading effect during weight-bearing activities [5]. In patients with knee OA, pain and disability are major problems. This in turn leads to decreased physical functioning and greater difficulty in performing activities of daily living. Physical disability is associated with the derangement of locomotor functions such as walking, ascending or descending stairs, sitting and standing, which are essential for the maintenance of daily activities [2].

Walking speed is a common performance measure of mobility and an important indicator of current health and well-being in older adults [6]. Individuals with knee OA have difficulty with walking, and tend

Correspondence address: Omoyemi O. Ogwumike, Department of Physiotherapy, College of Medicine, University of Ibadan, Queen Elizabeth Road UCH Campus, Ibadan 23402, Nigeria, e-mail: yemfide@yahoo.com

Received: August 21, 2018

Accepted for publication: December 13, 2018

Citation: Ogwumike OO, Musa SB. Relationships among walking speed, selected clinical symptoms, and exercise self-efficacy in individuals with knee osteoarthritis. Hum Mov. 2019;20(2):79-84; doi: https://doi.org/10.5114/hm.2019.81023. 
to walk slower than controls [7]. In these patients, decreased walking speed is associated with joint space narrowing, increased concentrations of inflammation mediators, and pain [8]. To achieve optimal health benefits, it is imperative that individuals with knee $\mathrm{OA}$ are able to maintain a relative physically active lifestyle contrary to sedentariness which is inflicted by the osteoarthritic condition. This underscores the importance of being physically active in spite of the health condition and, in essence, emphasizes the role of exercise self-efficacy.

Previous studies indicate that exercise self-efficacy is a powerful predictor of physical activity behaviour, which enhances health and wellbeing for older adults [9-12]. Self-efficacy is a cognitive mediator that molds the shape of illness and may improve compliance with prescribed therapies and exercise regimens [13]. According to Bandura [14], self-efficacy is defined as an individual's judgment of their capability to organize and execute actions needed to perform an activity, and is largely influenced by past performance and accomplishments. Accordingly, self-efficacy explains a large portion of the variance in performance of physical activities like walking in older adults with knee OA $[15,16]$. In view of the prevalent nature of knee OA in the Nigerian populace [3, 4], it is quite important to investigate the possibility of any relationship that may be in place among selected clinical symptoms (pain, stiffness, and physical function), walking speed, and exercise self-efficacy in individuals with knee OA. This could enable effective planning of interventional strategies and setting rehabilitation goals for individuals with knee OA.

\section{Material and methods}

\section{Participants}

The study participants were individuals with clinical diagnosis of knee OA who had been managed in selected public hospitals, including University College Hospital, Ring Road State Hospital, and Adeoyo State Hospital, Yemetu - all in Ibadan, Oyo State, Nigeria. The hospitals were major referral centres in the Ibadan metropolis and their selection was based on convenience and availability of patients with knee OA. The participants were recruited after the rationale for the study had been explained to them.

\section{Instruments}

1. The Western Ontario and McMaster (WOMAC) Osteoarthritis Index questionnaire was used to assess pain, stiffness, and functional limitations in the participants [17]. It is a self-administered questionnaire consisting of 24 items divided into 3 subscales (American College of Rheumatology):

(i) Pain (5 items): during walking, using stairs, in bed, sitting or lying, and standing.

(ii) Stiffness (2 items): after first waking and later in the day.

(iii) Physical function (17 items): descending stairs, ascending stairs, rising from sitting, standing, bending, walking, getting in/out of a car, shopping, putting on socks, taking off socks, rising from bed, lying in bed, getting in/out of bath, sitting, getting on/off toilet, heavy and light household duties.

Scoring: The Likert scale version of the WOMAC questionnaire was used, with the descriptors: none, mild, moderate, severe, and extreme, corresponding to an ordinal scale of $0-4$. Then the scores were summed for items in each subscale, with possible ranges as follows: $0-20$ for pain $(0=$ none; $1-10=$ mild $/$ moderate; $11-20=$ severe/extreme), $0-8$ for stiffness $(0=$ none; $1-4=\mathrm{mild} /$ moderate; $5-8=$ severe/extreme), $0-68$ for physical function $(0=$ none; $1-33=\mathrm{mild} /$ moderate; $34-68=$ severe/extreme). The sum of the scores for all 3 subscales gave the total WOMAC score, used to grade the type of knee OA experienced by the participants $(0-32=$ mild knee OA; 33-64 = moderate knee OA; 65-96 = severe knee OA).

2. Exercise self-efficacy scale, created by Neupert et al. [18], is a modified version of Bandura's exercise self-efficacy scale [14]. It was used to assess exercise self-efficacy in the participants. The test questions were scored on a scale of $1-4$, with the following descriptors: not sure at all $=1$; a little sure $=2$; pretty sure $=$ 3 ; very sure $=4$. The total score is calculated by summing the scores for all questions. This scale has a range of total scores of 9-36. The exercise self-efficacy was reported as low (9-18), moderate (19-27), or high (28-36).

3. Twenty-meter walk test was used to assess the walking speed of participants who walked 20 metres [19] at a self-selected pace at the hallway in the physiotherapy department of each hospital where data were collected. The time taken to walk this distance was evaluated with a stop watch. The procedure was repeated 3 times, and an average walking speed was evaluated, where walking speed $(\mathrm{m} / \mathrm{s})$ was calculated as 20 metres/time taken (s).

Data analysis

Continuous variables were summarized with the use of means and standard deviation. Categorical vari- 
ables were summarized with frequencies and percentages. As for the normality test, it was observed that most of the data were skewed hence Spearman correlation analysis was performed to establish relationships among selected clinical symptoms (pain, stiffness, and physical function), walking speed, and exercise self-efficacy of the study subjects while alpha was set at 0.05 .

\section{Ethical approval}

The research related to human use has been complied with all the relevant national regulations and institutional policies, has followed the tenets of the Declaration of Helsinki, and has been approved by the

Table 1. Socio-demographic profile of participants

$$
(n=100)
$$

\begin{tabular}{|c|c|c|}
\hline Variables & $n$ & $\%$ \\
\hline \multicolumn{3}{|l|}{ Age (years) } \\
\hline $55-65$ & 25 & 25.0 \\
\hline $66-75$ & 61 & 61.0 \\
\hline $76-85$ & 13 & 13.0 \\
\hline $86-95$ & 1 & 1.0 \\
\hline \multicolumn{3}{|l|}{ Sex } \\
\hline Male & 22 & 22.0 \\
\hline Female & 78 & 78.0 \\
\hline \multicolumn{3}{|l|}{ Religion } \\
\hline Islam & 30 & 30.0 \\
\hline Christianity & 70 & 70.0 \\
\hline \multicolumn{3}{|l|}{ Marital status } \\
\hline Married & 62 & 62.0 \\
\hline Not married & 38 & 38.0 \\
\hline \multicolumn{3}{|l|}{ Tribe } \\
\hline Yoruba & 91 & 91.0 \\
\hline Igbo & 8 & 8.0 \\
\hline Other & 1 & 1.0 \\
\hline \multicolumn{3}{|l|}{ Occupation } \\
\hline Unemployed & 65 & 65.0 \\
\hline Employed & 35 & 35.0 \\
\hline \multicolumn{3}{|c|}{ Highest level of education } \\
\hline None & 2 & 2.0 \\
\hline Primary & 40 & 40.0 \\
\hline Secondary & 12 & 12.0 \\
\hline Tertiary & 46 & 46.0 \\
\hline \multicolumn{3}{|c|}{ Personal income } \\
\hline Low & 10 & 10.0 \\
\hline Middle & 48 & 48.0 \\
\hline Moderate & 27 & 27.0 \\
\hline High & 15 & 15.0 \\
\hline
\end{tabular}

authors' institutional review board or an equivalent committee.

\section{Informed consent}

Informed consent has been obtained from all individuals included in this study.

\section{Results}

The study involved 100 individuals with knee OA (22 males; 78 females), with modal age group 66-75 years, mean age $69.6 \pm 6.3$ years. Most of them (69\%) had bilateral knee OA (Table 1).

Relationship among clinical symptoms, walking speed, and exercise self-efficacy

Mean and standard deviation of walking speed of all the participants was $0.38 \pm 0.09 \mathrm{~m} / \mathrm{s}$ and the range was $0.49 \mathrm{~m} / \mathrm{s}$, from 0.12 to $0.61 \mathrm{~m} / \mathrm{s}$. The modal group with 66 participants $(66.0 \%)$ had moderate walking speeds of within $0.28-0.44 \mathrm{~m} / \mathrm{s}$. This is presented in Table 2.

The result of Spearman correlation analysis to determine the relationship between selected clinical symptoms (pain intensity, stiffness, and physical function) and walking speed, as well as exercise self-efficacy is presented in Table 3. Significantly weak negative correlations were observed among the selected clinical symptoms and walking speed. Furthermore, pain intensity of knee OA individuals significantly and weakly correlated negatively with exercise self-efficacy, while stiffness and physical function were significantly but moderately negatively correlated with exercise selfefficacy.

\section{Discussion}

This study investigated the relationships between some selected clinical symptoms (pain, stiffness, and physical function), walking speed, and exercise selfefficacy among individuals with knee OA. The mean total WOMAC score of the participants showed that most had mild to moderate knee OA. This is in agreement with the findings of Gleicher et al. [20], who revealed that older adults, aged 60 years and above, had mild to moderate knee OA rather than severe or disabling knee OA. In addition, about half of the participants reported low exercise self-efficacy and 66.0\% had moderate walking speed. This is understandable because knee OA is a disabling condition and therefore may discourage active participation in exercise. 
Table 2. Clinical characteristics of the participants

$$
(n=100)
$$

\begin{tabular}{lrcc}
\hline Variables & $n$ & Mean $\pm S D$ & Median (IQR) \\
\hline Pain intensity & & & \\
None & 0 & & \\
Mild/moderate & 77 & & \\
Severe/extreme & 23 & $8.14 \pm 3.2$ & $8.00(4.00)$ \\
\hline Stiffness & & & \\
None & 6 & & \\
Mild/moderate & 66 & & \\
Severe/extreme & 28 & $3.59 \pm 1.62$ & $(3.00)$ \\
\hline Physical function & & & \\
Low & 0 & & \\
Moderate & 81 & & \\
High & 19 & $23.2 \pm 9.84$ & $(15.5)$ \\
\hline Total WOMAC score & & & \\
Mild knee OA & 43 & & \\
Moderate knee OA & 57 & & \\
Severe knee OA & 0 & $34.93 \pm 13.69$ & \\
\hline Walking speed (m/s) & & & \\
$0.12-0.27$ & 13 & & \\
$0.28-0.44$ & 66 & & \\
$0.45-0.61$ & 21 & $0.38 \pm 0.09$ & $0.12)$ \\
\hline
\end{tabular}

Exercise self-efficacy

\begin{tabular}{lrrr} 
Low & 54 & & \\
Moderate & 44 & & \\
High & 2 & $17.90 \pm 4.87$ & $18.00(6.0)$ \\
\hline
\end{tabular}

$I Q R$ - interquartile range, $S D$ - standard deviation, OA - osteoarthritis

Table 3. Spearman correlation analysis showing relationships among clinical symptoms, walking speed, and exercise self-efficacy

\begin{tabular}{|c|c|c|}
\hline Clinical & $\begin{array}{l}\text { Walking } \\
\text { speed }\end{array}$ & $\begin{array}{c}\text { Exercise } \\
\text { self-efficacy }\end{array}$ \\
\hline & $p$ & $\rho$ \\
\hline
\end{tabular}

\begin{tabular}{lrlrl}
\hline Pain intensity & -0.368 & $0.001^{*}$ & -0.330 & $0.001^{*}$ \\
\hline Stiffness & -0.234 & $0.019^{*}$ & -0.497 & $0.0001^{*}$ \\
\hline Physical function & -0.370 & $0.0001^{*}$ & -0.410 & $0.0001^{*}$ \\
\hline
\end{tabular}

$\rho$ - Spearman's rho, $p$ - probability

* significant results
Previous studies by Harrison [15] and Maly et al. [16, 21] also reported that patients with knee OA had low self-efficacy and low walking speed. Most subjects in this study presented mild to moderate knee stiffness. Knee stiffness had a negative relationship with walking speed and exercise self-efficacy. This indicates that the greater the degree of stiffness experienced by individuals with knee OA, the slower their walking speeds and the lower their exercise self-efficacy. Dixon et al. [22] observed that knee stiffness in walking was significantly greater in the OA group than in the control group, reducing walking speeds.

Most of the participants had mild to moderate pain intensity, which negatively correlated with walking speed and with exercise self-efficacy. This may not be unconnected with the fact that self-efficacy has been established to be a treatment-responsive mediator of illness and shown to improve the clinical outcome in patients with several types of chronic disease, including arthritis and osteoporosis [23]. Knee OA and ageing are associated with functional limitation problems, and ageing is found to be more associated with knee OA than with other types of OA [24]. In this study, physical function was also negatively correlated with walking speed and exercise self-efficacy. This is in line with the findings of Kim et al. [25], who reported that physical disability associated with radiographic changes in knee OA had a strong influence on exercise self-efficacy in older adults. This reduction in physical function in individuals with knee OA also led to low physical performance and a decrease in their velocity of walking [26]. In essence, individuals with knee OA presenting with varied clinical symptoms had an indirect impact of these symptoms on their walking speed and exercise self-efficacy. It is therefore imperative that positive efforts need to be made to introduce effective techniques of management to individuals with knee OA to address their pain and physical function [27].

\section{Conclusions}

In this study, individuals with knee OA had low exercise self-efficacy, low walking speed, and reduced physical function, probably because of the debilitating effects of the condition. The findings underscore the importance of effective management of clinical symptoms presented in patients with knee OA. This will in turn enhance their exercise self-efficacy and walking speed. 


\section{Disclosure statement}

No author has any financial interest or received any financial benefit from this research.

\section{Conflict of interest}

The authors state no conflict of interest.

\section{References}

1. Lozada CJ. Osteoarthritis treatment and management. Available from: http://emedicine.medscape.com/ article/330487-treatment.

2. Ozcetin A, Ataoglu S, Kocer E, Yazycy S, Yildiz O, Ataoglu A, et al. Effects of depression and anxiety on quality of life of patients with rheumatoid arthritis, knee osteoarthritis and fibromyalgia syndrome. West Indian Med J. 2007;56(2);122-129; doi: 10.1590/ S0043-31442007000200004.

3. Ogunlade SO, Alonge TO, Omololu AB, Adekolujo OS. Clinical spectrum of large joint osteoarthritis in Ibadan, Nigeria. Eur J Sci Res. 2005;11:116-122.

4. Akinpelu AO, Alonge TO, Adekanla BA, Odole AC. Prevalence and pattern of symptomatic knee osteoarthritis in Nigeria: a community-based study. Internet J Allied Health Sci Pract. 2009;7(3).

5. Merle-Vincent F, Vignon E, Brandt K, Piperno M, Coury-Lucas F, Conrozier TP, et al. Superiority of the Lyon schuss view over the standing anteroposterior view for detecting joint space narrowing, especially in the lateral tibiofemoral compartment, in early knee osteoarthritis. Ann Rheum Dis. 2007;66(6):747-753; doi: 10.1136/ard.2006.056481.

6. Studenski S, Perera S, Patel K, Rosano C, Faulkner K, Inzitari M, et al. Gait speed and survival in older adults. JAMA. 2011;305(1):50-58; doi: 10.1001/jama.2010. 1923.

7. Abbasi-Bafghi H, Fallah-Yakhdani HR, Meijer OG, de Vet HCW, Bruijn SM, Yang L-Y, et al. The effects of knee arthroplasty on walking speed: a meta-analysis. BMC Musculoskelet Disord. 2012;13:66; doi: 10.1186/14712474-13-66.

8. McDaniel G, Renner JB, Sloane R, Kraus VB. Association of knee and ankle osteoarthritis with physical performance. Osteoarthritis Cartilage. 2011;19(6): 634-638; doi: 10.1016/j.joca.2011.01.016.

9. Burton LC, Shapiro S, German PS. Determinants of physical activity initiation and maintenance among community-dwelling older persons. Prev Med. 1999; 29(5):422-430; doi: 10.1006/pmed.1999.0561.

10. Resnick B, Nigg C. Testing a theoretical model of exercise behavior for older adults. Nurs Res. 2003;52(2):8088; doi: 10.1097/00006199-200303000-00004.

11. Smith JC, Zalewski KR, Motl RW, Hart MV, Malzahn J. The contributions of self-efficacy, trait anxiety, and fear of falling to physical activity behavior among residents of continuing care retirement communities. Ageing Res. 2010;1(1):6; doi: 10.4081/ar.2010.e4.
12. Kroll T, Kratz A, Kehn M, Jensen MP, Groah S, Ljungberg IH, et al. Perceived exercise self-efficacy as a predictor of exercise behavior in individuals aging with spinal cord injury. Am J Phys Med Rehabil. 2012;91(8): 640-651; doi: 10.1097/PHM.0b013e31825a12cd.

13. Hanan SA, Sahar YM. Perceived self-efficacy and commitment to an exercise in patients with osteoporosis and osteoarthritis. J Am Sci. 2011;7(8):315-323.

14. Bandura A. Self-efficacy: toward a unifying theory of behavioral change. Psychol Rev. 1977;84(2):191-215; doi: 10.1016/0146-6402(78)90002-4.

15. Harrison AL. The influence of pathology, pain, balance, and self-efficacy on function in women with osteoarthritis of the knee. Phys Ther. 2004;84(9):822-831; doi: 10.1093/ptj/84.9.822.

16. Maly MR, Costigan PA, Olney SJ. Contribution of psychosocial and mechanical variables to physical performance measures in knee osteoarthritis. Phys Ther. 2005;85(12):1318-1328; doi: 10.1093/ptj/85.12.1318.

17. Bellamy N. WOMAC osteoarthritis index user guide. Version VII. Brisbane; 2005.

18. Neupert SD, Lachman ME, Whitbourne SB. Exercise self-efficacy and control beliefs: effects on exercise behaviour after an exercise intervention for older adults. J Aging Phys Act. 2009;17(1):1-16; doi: 10.1123/japa. 17.1.1.

19. Motyl JM, Driban JB, McAdams E, Price LL, McAlindon TE. Test-retest reliability and sensitivity of the 20-meter walk test among patients with knee osteoarthritis. BMC Musculoskelet Disord. 2013;14:166; doi: 10.1186/1471-2474-14-166.

20. Gleicher Y, Croxford R, Hochman J, Hawker G. A prospective study of mental health care for comorbid depressed mood in older adults with painful osteoarthritis. BMC Psychiatry. 2011;11:147; doi: 10.1186/ 1471-244X-11-147.

21. Maly MR, Costigan PA, Olney SJ. Self-efficacy mediates walking performance in older adults with knee osteoarthritis. J Gerontol A Biol Sci Med Sci. 2007; 62(10):1142-1146; doi: 10.1093/gerona/62.10.1142.

22. Dixon SJ, Hinman RS, Creaby MW, Kemp G, Crossley KM. Knee joint stiffness during walking in knee osteoarthritis. Arthritis Care Res. 2010;62(1):38-44; doi: 10.1002/acr.20012.

23. Galland LD. A new definition of patient centered medicine. In: Kligler B, Lee RA (eds.). Integrative medicine: principles for practice. New York: McGrow-Hill; 2004; 71-104.

24. Misra D, Felson DT, Silliman RA, Nevitt M, Lewis CE, Torner J, et al. Knee osteoarthritis and frailty: findings from the Multicenter Osteoarthritis Study and Osteoarthritis Initiative. J Gerontol A Biol Sci Med Sci. 2015;70(3):339-344; doi: 10.1093/gerona/glu102.

25. Kim KW, Han JW, Cho HJ, Chang CB, Park JH, Lee JJ, et al. Association between comorbid depression and osteoarthritis symptom severity in patients with knee osteoarthritis. J Bone Joint Surg Am. 2011;93(6):556563; doi: 10.2106/JBJS.I.01344. 


\section{HUMAN MOVEMENT}

O.O. Ogwumike, S.B. Musa, Walking speed and knee osteoarthritis

26. Marks R. Depressive symptoms among communitydwelling older adults with mild to moderate knee osteoarthritis: extent, interrelationships, and predictors. Am J Med Stud. 2013;1(3):11-18; doi: 10.12691/ ajms-1-3-1.

27. Egwu OR, Ayanniyi OO, Adegoke BOA, Olagbegi OM, Ogwumike OO, Odole AC. Effect of self-management education versus quadriceps strengthening exercises on pain and function in patients with knee osteoarthritis. Hum Mov. 2018;19(3):64-74; doi: 10.5114/hm.2018. 76081. 